\title{
Problems and Countermeasures in the Process of Applying Multimedia Technology in Basketball Teaching
}

\author{
Bixia Yan \\ Faculty of General Education, Chongqing Vocational and Technical University of Mechatronics, Bishan, 402760 Chongqing, China \\ Correspondence should be addressed to Bixia Yan; 171445003@cqvie.edu.cn
}

Received 26 March 2021; Revised 17 April 2021; Accepted 31 May 2021; Published 17 August 2021

Academic Editor: Wenqing Wu

Copyright ( 2021 Bixia Yan. This is an open access article distributed under the Creative Commons Attribution License, which permits unrestricted use, distribution, and reproduction in any medium, provided the original work is properly cited.

\begin{abstract}
Nowadays, there are few researches on using multimedia animation technology to assist basketball tactics teaching and training in college physical education. The research of multimedia animation assisting basketball tactics teaching can help promote the current teaching mode, teaching environment, and teaching methods. From the perspective of the development trend of modern education and the benefits of multimedia technology in physical education teaching, this article demonstrates the inevitability of applying multimedia technology in college basketball teaching and demonstrates the feasibility of implementing multimedia physical education in colleges and universities from the three aspects of multimedia teaching environment, teacher teaching ability analyzes the factors that affect the effect of multimedia-assisted teaching. Students' acceptance characteristics of the multimedia environment are obtained. Relevant research results and suggestions on the use of multimedia animation in basketball tactics teaching will be submitted. Research shows the ability and student's learning ability. It analyzes the effects of multimediaassisted teaching in basketball tactics. In this article, at $84 \%$ of teachers feel that multimedia-assisted teaching is better. However, some objective factors restrict teachers' use of multimedia-assisted teaching methods. Among them, poor production technology and inconvenient use are the main factors that teachers think affect the application of multimedia-assisted teaching methods in actual teaching, and these influencing factors are difficult to eliminate in a short time.
\end{abstract}

\section{Introduction}

Multimedia network teaching can achieve a wider range of information resource sharing because of its wide coverage. Teachers can also use various forms of teaching methods to enrich and invigorate the classroom, which also helps improve the effect of teaching applications. Multimedia network teaching is more important to support collaborative learning. Through mutual cooperation and communication, students will have a deeper understanding of the content of learning, a broader learning mindset, more diverse learning methods, more efficient intelligence training, and higher learning efficiency. Therefore, the subject research provides practical guidance for improving the application effect of basketball teaching.

The development of multimedia network teaching abroad is relatively mature, and many countries have widely used network teaching. And many scholars have learned it. For example, Salski et al. analyzed the application of multi- media technology in basketball teaching, training, and learning from different perspectives. It is generally believed that multimedia technology can help teachers and students communicate effectively and improve teaching. In quality and effect, it enhances the intuitive teaching effect, stimulates students' interest in learning, helps students understand and master basketball techniques and tactics, and can improve learning efficiency [1]. Wahab expands the cooperation space between multimedia technology and college basketball leagues, improves the more user friendly operation efficiency of multimedia technology, strengthens the linkage with the audience of the college basketball league, reasonably formulates the game schedule, and realizes multimedia technology and wonderful college basketball mutual benefit and win-win of the league [2].

In my country, Li et al. has carried out computer training for teachers at all levels. In terms of training teachers' multimedia teaching abilities, various forms have been adopted, such as centralized school district training (inviting experts 
with profound multimedia teaching theories and computer operator teachers for tutoring), school-based training (group training in schools), and individual tutoring (teach multimedia teaching skills in one-to-one form) [3]. Haiqing allows the computer program to play the role of the "midwife" and continuously asks students new and challenging questions in the ongoing dialogue and hardly provides any answers to the students, thereby enhancing students' thinking ability and improving thinking method [4]. Ying et al. uses computer animation production technology to produce multimedia-assisted teaching virtual animations in accordance with the actual requirements of teaching and understand the technical difficulty of making sports-assisted teaching animations. In the process of using multimedia animation to assist teaching, I explore the problems in the process of teaching implementation in combination with different teaching methods and study the effect of sports multimedia virtual animation-assisted teaching [5].

This article selects the two contents of the basic cooperation of basketball tactics, the screen and the exchange of defense, and designs the multimedia teaching courseware. Through the teaching experiment and the students' evaluation of the teaching effect, the effect of the application of multimedia-assisted teaching in the basketball tactics cooperation is analyzed. The majority of sports workers design and produce multimedia teaching courseware to provide references. In order to improve teaching conditions and give full play to the potential of multimedia-assisted teaching, multimedia technology combined with flexible and diverse teaching organization forms is used, and the use scientific, intuitive, visualized, and interesting sports teaching mobilizes students' interest in learning, stimulates their enthusiasm for learning, cultivates students' sports ability, promotes the overall development of students' basketball skills and tactics, and lays the foundation for lifelong physical exercise.

\section{Problems and Countermeasures in the Process of Applying Multimedia Technology to Basketball Teaching}

\subsection{Problems Existing in the Process of Applying Multimedia Technology to Basketball Teaching}

2.1.1. The Quality of Teachers Using Multimedia Network Technology in Teaching is Generally Not High

(1) Relatively lagging in thought

Although the leaders of the school attach great importance to the classroom teaching application of multimedia network technology, the deep-rooted influence of the traditional teaching mode of our country for thousands of years on many teachers of the school, especially the old teachers, resulted in them having insufficient knowledge of multimedia network technology, and the production of courseware is not enough. It is so handy, and it takes a lot of effort. Therefore, some teachers are resistant to the teaching methods of multimedia and network technology. Moreover, there are not many corresponding encouragement policies in schools.
The new classroom teaching methods put forward higher requirements for teachers. For them, who have a relatively stable working environment and have formed their own teaching habits, they have greatly increased their workload and brought them a sense of psychological insecurity. Therefore, they tend to be more inclined to impart knowledge in accordance with traditional teaching methods $[6,7]$. In addition, most students report that they are accustomed to the traditional exam-oriented education and are not very comfortable with the new teaching methods. In addition, the individual subjective consciousness is not strong, which makes independent learning more difficult.

\section{(2) Improper role positioning}

For example, in the teaching process of multimedia chemistry class, teachers just blindly let students learn on the Internet without monitoring, allowing students to discuss the reactions between various compounds, completely out of the subject of chemistry class. The teaching order is disordered, the teaching theme is not clear, and the learning effect is not obvious. Not only the advantages of learning under the multimedia network technology are not reflected, but also the traditional teaching tasks cannot be effectively completed, let alone the emotional exchange between teachers and students $[8,9]$.

(3) Attach importance to human-computer interaction and ignore interpersonal interaction

In the multimedia network teaching environment, teachers often pay more attention to the interaction between teachers and students and computers, and the direct interaction between people has become indirect. Some teachers have no emotional interaction design in the teaching process, rarely move around in the classroom, rarely write on the blackboard, click the mouse on the main console to explain, and lack the attention to students and emotional communication, making the classroom atmosphere very dull $[10,11]$. Many students also report that they feel that they are learning in a mechanical environment, transforming into learning robots, lonely, confused, and confused and dull, leading to loss of interest and confidence in learning.

2.1.2. Students Have Deviations in Learning Using Multimedia Network Technology. Multimedia network classroom teaching provides a wealth of learning resources, which also requires students to have a strong ability to learn independently, and the level of students in this school is quite different and there are certain difficulties [12,13]. Students who have a good knowledge base and know how to learn believe that personalized learning and freedom allow them to arrange their time more reasonably, and they will obtain more information per unit of time, while students with a poor foundation and weaker self-discipline do not have a teacher. In the case of supervision and guidance, they often focus on the rich pictures, learning is easy to fatigue, the attention is easy to be distracted, and the focus and goals of learning are not clear. Facing a large amount of information, they do not know how to choose and cannot give feedback on 
their own learning in time. Not to be able to supervise their own preview and review will ultimately affect the learning effect.

\subsubsection{The Management of Multimedia Network Technology in Schools Is Relatively Lagging Behind}

(1) Ignore computer network maintenance due to insufficient funds

Although the school leaders want to increase investment in multimedia networks, because the school has just moved to a new campus, large-scale enrollment and new construction of the campus have to be carried out, resulting in relatively insufficient investment in teaching funds; on the other hand, the speed of computer updates very fast, it will be obsolete if it is not updated for three years, and the investment in network technology and multimedia is huge. It takes at least 100,000 to build a fully functional multimedia classroom, and the investment in network construction is even greater $[14,15]$. In addition, the school has a serious shortage of full-time personnel for equipment maintenance. It is often one person doing three people's work. In addition, there is not enough sense of responsibility and the technical level is not high. It often appears that the teaching software is out of date and has not been updated, and failures cannot be timely. Over time, the resolved phenomenon has consumed the patience of teachers and students and also affected the teaching progress.

(2) Inadequate feedback and monitoring using multimedia network teaching

Quality supervision and scientific management are important measures to ensure teaching quality and improve teaching effectiveness. For example, although the school's research on the network teaching model is in full swing, the corresponding teaching monitoring, evaluation, and feedback mechanisms have not been implemented into a system. Due to the lack of interactive initiative of teachers in the teaching process, the monitoring of students' learning seems weak $[16,17]$. Some even think that as long as they provide support, students will definitely use it, but the actual situation is that students' learning arbitrariness becomes greater, and their self-control and awareness of autonomy are weakened.

\subsection{Countermeasures in the Process of Applying Multimedia} Technology to Basketball Teaching. The biggest difference between multimedia-assisted teaching and traditional teaching methods is that the teaching media used in teaching activities is different. It uses multimedia computers and some external output devices as communication media and spreads in the form of text, graphics, images, sound, video, etc. In terms of teaching information, teaching resources are obtained from digital publications, networks, selfdeveloped production, and other forms. The changes in teaching methods have changed the status and role of teachers in teaching and students' learning styles. Therefore, in multimedia-assisted teaching, the teaching of middle school teachers and the learning of students must adapt to the new teaching methods $[18,19]$. According to the characteristics of multimedia-assisted teaching, the implementation of multimedia-assisted teaching must meet three conditions, namely, the computer teaching environment must meet the needs of multimedia teaching, teachers must have multimedia teaching capabilities, and students must have the ability to learn in a multimedia teaching environment.

\section{(1) The social environment of multimedia teaching}

With the strengthening of my country's comprehensive national strength, education investment continues to grow, and campus networking and digital construction have begun to take shape, providing economic conditions and material foundations for the application of multimedia technology in teaching $[20,21]$. The country's continuous high investment in education has made great progress in the construction of campus networks. At present, all universities in our country have basically completed broadband campus networks that can better transmit multimedia information, which provides for the high-tech construction of education and the upgrading and transformation of education. A solid economic foundation and a good environment make it possible for multimedia technology to be widely used in teaching $[22,23]$.

\section{(2) Multimedia hardware environment construction}

The demonstration multimedia teaching environment has changed the traditional simple chalk and blackboard teaching methods. It uses a variety of media to stimulate students' senses, which is conducive to students' acceptance of knowledge and strengthening memory. However, in this form of multimedia teaching environment, students are still in passive status, the teacher demonstrates that students watch, lack of student participation, is not conducive to exerting the initiative of students in learning and developing students' personality $[24,25]$. Therefore, schools with a better campus network can build a sports multimedia teaching environment into a shared type.

(3) Teachers must have multimedia-assisted teaching capabilities

Only with good hardware cannot be considered that multimedia sports teaching can proceed smoothly and guarantee the quality of teaching. Teachers play a leading role in teaching practice. The basis of multimedia technology is computer technology. The teacher's computer application ability directly affects the effect of multimedia teaching. If teachers lack modern high-tech literacy, the use of multimedia teaching is still empty talk. Due to the relationship between history and disciplines, the computer level of the physical education teachers in our country was generally low in the past, which became a bottleneck in the application of multimedia technology in the field of physical education. Now with the popularization of computer education and the continuing education of teachers, teachers' computer skills have generally improved. Those who can use computers and the Internet proficiently or more proficiently account for the vast 
majority of physical education teachers. They are proficient in computer operations and capable of multimedia teaching. Therefore, the implementation of multimedia-assisted teaching in the field of sports has the guarantee of qualified teachers.

\subsection{Countermeasures to Improve the Application of Multimedia Network Technology in Classroom Teaching}

(1) Leaders should look at the application value of multimedia network technology from the long-term development of teaching

From a long-term perspective, the correct understanding of Gao teachers should be improved. First of all, the school can set up a special group led by the teaching department and specifically responsible for each teaching and research group and organize teachers to learn advanced and systematic education and teaching concepts in the way of assembly concentration or subject grouping. For example, the relevant theories of multimedia network teaching (including cognitivism, behaviorism, constructivism, and multimedia learning cognitive theories), as well as advanced teaching design theories and methods, are collected, printed, and bound into a book and distributed to various subject groups. Organize teachers to study seriously and let them realize the advantages of online teaching different from traditional teaching.

(2) Teachers should understand multimedia network technology from the reform of teaching methods and means

Multimedia network teaching is a new teaching method under the background of the new era. It mainly displays teaching content intuitively and vividly through images, sounds, and text, which greatly stimulates interest in learning, activates students' thinking, and improves the efficiency and efficiency of learning (positivity). In the multimedia network technology teaching environment, education and teaching activities are carried out. As long as the teacher carefully prepares the courseware, that is, or the web page, before class, effective teaching can be carried out. In this environment, teachers can not only use multimedia to strengthen teaching but also the content is systematic, scientific, intuitive, and interesting.

\section{Basketball Teaching Experiment under Multimedia Technology}

3.1. Selection of Teaching Experiment Objects. The choice of experiment subjects not only needs to study and master basic basketball skills such as passing, playing, throwing, and moving but also students who have little understanding of the basics of basketball tactics and rarely learn basketball knowledge independently in their spare time. This experiment chooses Northwest Normal University's two female classes in the second-year "University Sports" basketball option as the experimental subjects: one class was used as the experimental group (32 students), and the other class (35 people) was used as the control group.
3.2. Experimental Method. According to the research design, the experimental subjects were randomly grouped and taught. In order to ensure the objectivity of the teaching experiment, in addition to the method of random grouping, in the teaching experiment process, I personally take charge of the whole process of basketball tactics teaching for the general group and the experimental group and pay attention to the design of the content of the teaching plan to ensure the tactical explanation Consistent with the tactical practice form, the tactical teaching of the general group is mainly based on traditional teaching methods, while the tactical teaching of the experimental group is a combination of traditional teaching methods and multimedia-assisted teaching methods. In basketball tactics teaching, multimedia animation methods are only used as teaching aids, and the use of multimedia occupies a relatively small proportion of the classroom time and is only used when necessary. The only different influencing factor for the two groups of students during the teaching experiment is the use of multimediaassisted teaching animation. Aiming at the problems in tactical teaching, the ordinary group mainly solves the problems through traditional teaching methods, while the experimental group solves the problems through the combination of traditional teaching methods and multimedia auxiliary methods.

3.3. Questionnaire Survey Method. Relevant basketball teaching experts, teachers, and students are invited to evaluate the made teaching animation courseware and survey expert teachers and students in the form of questionnaires. Student questionnaires are distributed in class to ensure the questionnaire recovery rate. A total of 112 questionnaires were distributed, including 100 student questionnaires, with a recovery rate of $98 \%$ and an efficiency of $90 \%$, and 10 expert and teacher questionnaires, including 6 associate professors, 4 lecturers, and 2 teaching assistants. 20 questionnaires were recovered, the recovery rate was $80 \%$, and the effective rate was $90 \%$.

\section{Research and Analysis of Basketball Teaching Experiment under Multimedia Technology}

4.1. There Is a Certain Feasibility of Multimedia Animation to Assist Basketball Tactics Teaching. This paper studies the nature of the learner's learning process under the condition of multimedia assistance. Through the study of the interaction between the learner and the multimedia environment during the learning process, the three essential characteristics of the learning process in the learner's interaction with the multimedia prototype were proven. The learner believes that the multimedia environment is necessary; the execution of intellectual ability under the interaction with the multimedia system, the exploration, and the search for the motivation of learning are helpful to learning. The experimental results are shown in Figure 1.

It can be seen from Figure 1 that students have greater consistency in their choice of multimedia animationassisted teaching methods. $93 \%$ of students like this assisted teaching method, but $6 \%$ of students dislike this assisted 


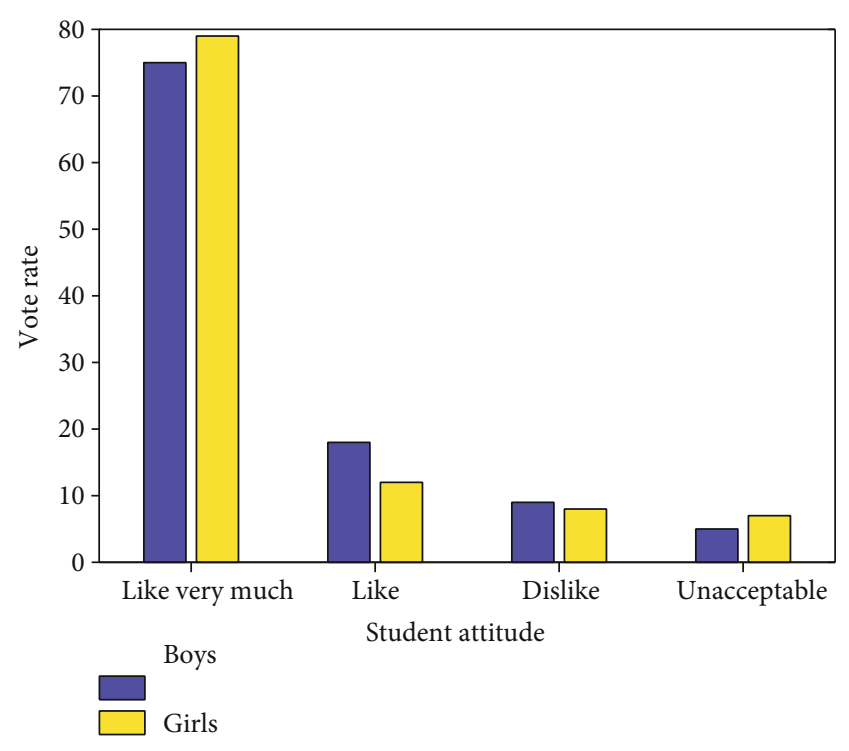

FIGURE 1: Students' attitudes towards animation-assisted teaching method.

teaching method. There are two main reasons for the attitude of $6 \%$ of the students: this teaching method is quite different from the traditional teaching method, and it is difficult for them to accept it in a short time; they are more accustomed to traditional tactical expression methods, and it is difficult to change their concepts. Although this group of students is a minority, in teaching, it is necessary to adopt the principle of differentiated treatment for this group of students. On the one hand, appropriate methods to change students' understanding of multimedia animation-assisted teaching were adopted, and on the other hand, traditional tactical teaching methods and forms are appropriately combined, to take care of this part of the students. Generally speaking, students still agree with the aid of multimedia animation methods and are subjectively easy to accept. After the students' interest in learning is stimulated, their learning attention will increase accordingly, which will help learn tactical knowledge and content. In basketball tactics teaching, the teaching of tactical knowledge should be carried out when students' attention is relatively concentrated in order to achieve better teaching results.

Although students have a strong tendency to use multimedia technology, in the current realistic basketball teaching, the application of multimedia-assisted teaching methods is not satisfactory. The survey shows that in the past learning process of students, only $30 \%$ of the teachers have used the video format to teach. Fewer people use multimedia animation technology to assist tactical teaching in basketball teaching. The survey results are shown in Table 1 and Figure 2.

From Figure 2, we can see that the proportion of students who have received multimedia-assisted teaching in the past is very small, and most students focus on the two options of seldom or not using multimedia-assisted teaching. This reflects the current application status of multimedia technology in college physical education from one aspect. According to the teacher survey questionnaire, teachers have a certain
TABle 1: Multimedia usage survey of experimental group.

\begin{tabular}{lcccc}
\hline & $\begin{array}{c}\text { Frequently } \\
\text { used }\end{array}$ & $\begin{array}{c}\text { Not often } \\
\text { used }\end{array}$ & Rarely use & $\begin{array}{c}\text { Never } \\
\text { used }\end{array}$ \\
\hline Test group 1 & 0 & 3 & 7 & 8 \\
Test group 2 & 1 & 2 & 5 & 10 \\
\hline
\end{tabular}

understanding of multimedia courseware-assisted teaching, and teachers subjectively accept multimedia-assisted teaching methods and are willing to improve current teaching methods and methods when conditions permit. In actual teaching, $84 \%$ of teachers feel that multimedia-assisted teaching is better. However, some objective factors restrict teachers' use of multimedia-assisted teaching methods. Among them, poor production technology and inconvenient use are the main factors that teachers think affect the application of multimedia-assisted teaching methods in actual teaching, and these influencing factors are difficult to eliminate in a short time.

4.2. Screening Coordination Evaluation Results. In order to further analyze the influence of multimedia-assisted teaching on the teaching effect of shielding cooperation, the results of statistical analysis of the seven connotative features of shielding cooperation are shown in Figure 3.

Through analysis, it is concluded that the experimental group and the control group have significant differences in the scores of the three connotative characteristics of the time, space, and cooperation of the screen cooperation, which shows that the application of multimedia-assisted teaching in the screen cooperation teaching is helpful to help students understand the timing, location, and location of cooperation. There are significant effects in terms of moving routes and overall structure of tactical coordination. There is no difference in the scores of the four connotative features of covering coordination, regularity, adaptability, effectiveness, and technical action, indicating that the application of multimedia-assisted teaching has little effect on the regularity, adaptability, effectiveness, and movement technique of covering coordination. The grasp of the rules, the response to the situation on the field, and the formation of technical movements must be accumulated in a lot of practice and competition.

In order to further analyze the impact of different teaching methods on the exchange defense teaching effect, the statistical analysis results of the connotative characteristic scores of the 7 exchange defense cooperations are shown in Figure 4. The average time characteristic score of the exchange cooperation is 3.52 in the experimental group. The control group was 3.26 .

Through analysis, it is found that the experimental group and the control group have significant differences in the scores of the two scoring indicators of exchange defense cooperation and cooperation. This shows that the application of multimedia-assisted teaching in exchange defense cooperation teaching can help students understand the movement route of exchange defense cooperation. The overall structure 


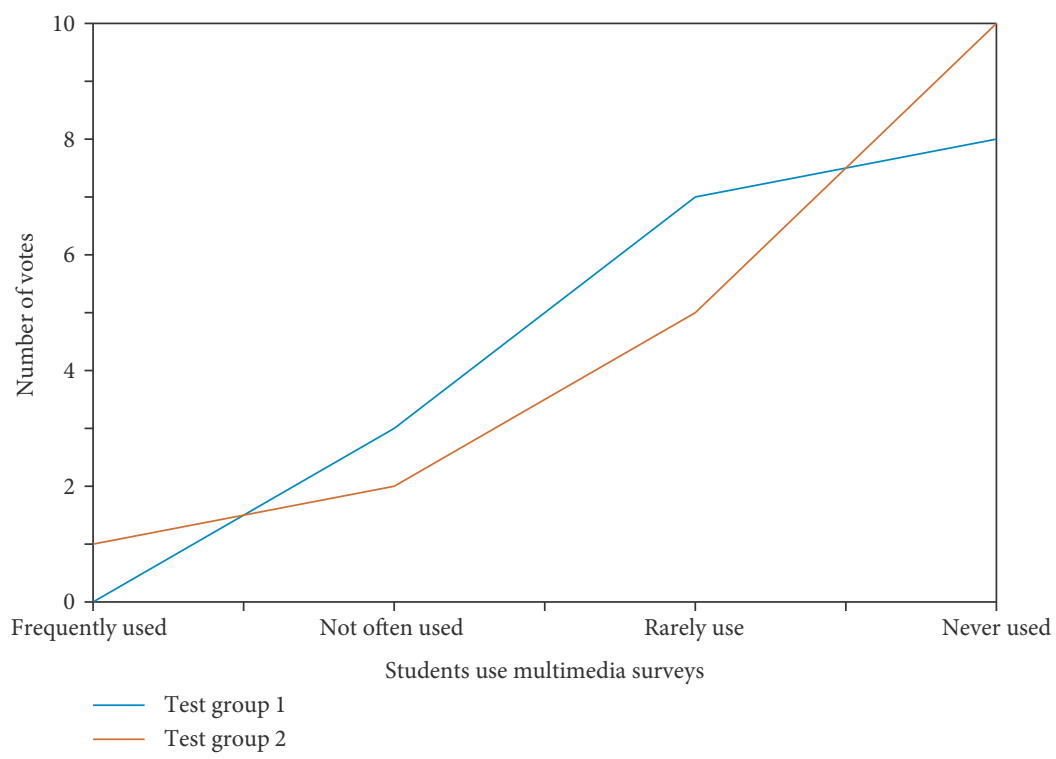

Figure 2: Multimedia usage survey of experimental group.

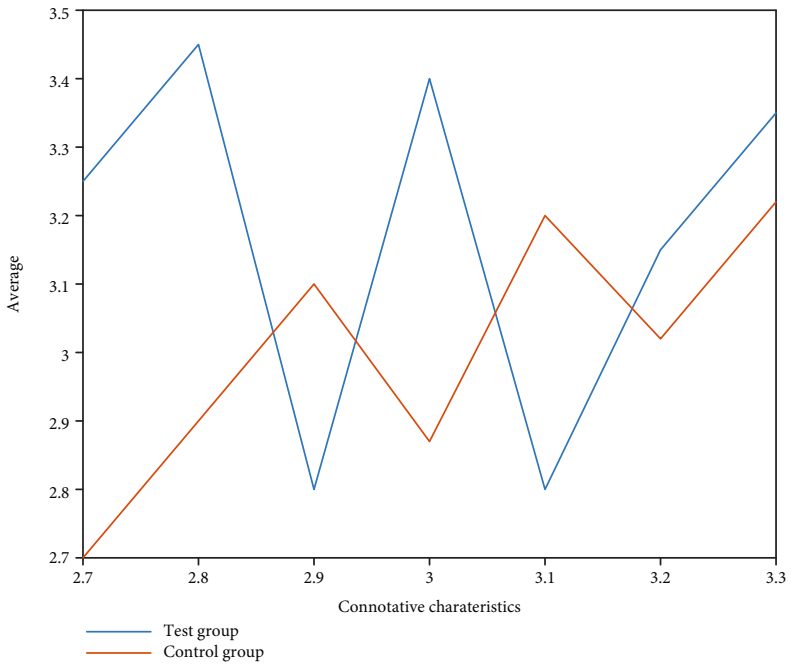

FIgURE 3: Screening coordination scoring checklist.

of the coordination and the interaction between the players have significant effects; while the timeliness, adaptability, regularity, effectiveness, and technical movement learning of the exchange defense coordination have no significant difference compared with the conventional teaching methods, indicating that the application multimedia-assisted teaching has little effect on the timeliness, adaptability, regularity, effectiveness, and technical movements of exchange defense coordination. The analysis suggests that there is no significant difference in temporal characteristics because the exchange of defense coordination is a passive behavior of the defender based on the cooperation of the offensive player. The timing of the player's coordination, movement speed, and rhythm changes are affected by the timing of the offensive player's behavior, the influence of characteristics has little to do with the teaching methods adopted, and there is no signifi-

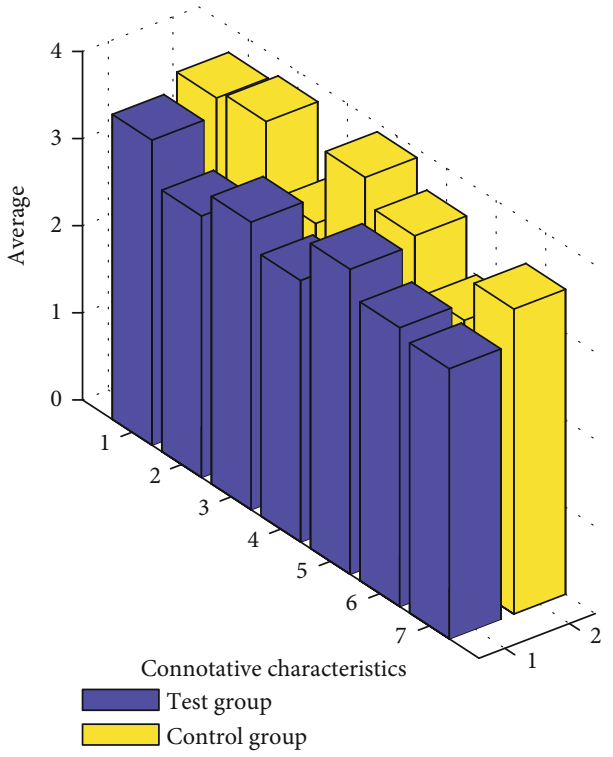

FIgURE 4: Single test result of the exchange defense coordination score.

cant difference in the adaptability, regularity, effectiveness, and technical movements of exchange defensive cooperation. This is because students' grasp of the rules, adaptability to the field situation, and technical movements in the formation, and so on need to accumulate in a lot of practice and competition.

\section{Conclusions}

The application of multimedia-assisted teaching in basketball tactics basic coordination teaching has a positive effect on students' understanding of the overall structure of tactical coordination, timing, movement routes, and interaction among players, while the formation of coordination 
techniques and on-the-spot adaptability have no significant effect. This is because the learning of basic basketball tactics is a process of thinking and physical exercises. In the basic teaching of basketball tactics, multimedia-assisted teaching should be combined with traditional teaching methods to give full play to the advantages of multimedia technology to help students understand tactics, establish the concept of tactical coordination, and form a preliminary awareness of tactical coordination, combined with traditional teaching methods, after a lot of practice and competition to be further strengthened, in practice and competition to further improve, through knowledge-practice-reunderstanding - the continuous cycle of "re-practice" process deepens, consolidates, and improves, and finally forms tactical awareness.

Most students believe that the use of multimedia-assisted teaching can intuitively express the teaching content in the form of text, graphics, images, videos, animations, etc., which can stimulate learning interest, improve learning enthusiasm, help understand the teaching content, and use multimediaassisted teaching methods. It can speed up the mastery of the basic cooperation of basketball tactics, and the teaching effect of the basic cooperation of basketball tactics with the aid of multimedia teaching methods is satisfactory. It can be seen that multimedia-assisted teaching is a teaching method recognized and welcomed by students.

Traditional teaching methods and multimedia animation-assisted teaching methods have their own strengths. Traditional basketball tactics teaching methods are difficult to explain a relatively complex new tactic in a short time and enable students to form a clearer tactical appearance and concept; it is not easy to demonstrate tactical cooperation and control the classroom process, but it can provide various effective practice methods that can help students master tactics; and under the aid of multimedia animation, students generally reflect better learning results, and teachers control easier the classroom process.

\section{Data Availability}

No data were used to support this study.

\section{Conflicts of Interest}

The author declares that they have no conflicts of interest.

\section{References}

[1] B. Salski, J. Cuper, P. Kopyt, and P. Samczynski, "Radar crosssection of sport balls in $0.8-40 \mathrm{GHz}$ range," IEEE Sensors Journal, vol. 18, pp. 7467-7475, 2018.

[2] N. A. Wahab, "The use of multimedia in increasing perceived knowledge and awareness of cyber-bullying among adolescents: a pilot study," Procedia-Social and Behavioral Sciences, vol. 176, no. 3, pp. 745-749, 2015.

[3] Z. Li, X. Wang, and H. Yu, "Application of multimedia technology in network course teaching," Modern Computer (Professional Edition), no. 24, pp. 80-83, 2018.

[4] D. Haiqing, "Analysis of the function of multimedia in the teaching of basketball special technology," Wireless Internet Technology, no. 15, pp. 69-70, 2015.
[5] Y. Xu, T. Ye, T. Yue, J. Wu, and P. Zhao, "The application of multimedia technology in teaching anatomy of anesthesiology," China Continuing Medical Education, vol. 9, no. 4, pp. 40-42, 2017.

[6] J. Xinxin and L. Jia, "The importance of multimedia application in junior high school English teaching," Journal of Jiamusi Education Institute, no. 7, p. 294, 2016.

[7] S. Wenxia, "Study on application of multimedia technology in physics teaching in senior high school," Wireless Internet Technology, no. 21, pp. 98-99, 2015.

[8] Y. Lin, "On the application of multimedia Technology in computer teaching in secondary vocational schools," Science \& Education Wenhui, no. 10, pp. 108-109, 2017.

[9] W. Jinsong, "Application of multimedia technology in orthopedics teaching," China Continuing Medical Education, vol. 8, no. 2, pp. 24-26, 2016.

[10] D. Hongyun, "On the application of hierarchical teaching method in basketball teaching in higher vocational colleges," Journal of Jiamusi Education College, no. 7, pp. 346-347, 2016.

[11] J. Wang and Y. Fengxian, The Application of Multimedia to High School English Teaching-_Take No. 6 Junior High School as an example, no. 48, 2017Charming China, 2017.

[12] H. Sheng, "On the application of multimedia technology in physical education teaching in primary and middle schools," Sports Science and Technology Literature Bulletin, vol. 27, no. 6, pp. 98-99, 2019.

[13] L. Huyi, "A study on strategies of optimizing college basketball teaching based on flipped classroom," Journal of Heihe University, vol. 10, no. 2, pp. 116-117, 2019.

[14] J. Dongsheng, "Application of sports education model in basketball teaching in higher vocational colleges," Journal of Xiangyang Vocational and Technical College, vol. 18, no. 4, pp. 5658, 2019.

[15] Z. Lichao, "An experimental research on TBL learning method in basketball teaching of medical specialty\%"TBL" experimental research on basketball teaching of medical specialty," Sports Products (Academic Edition), vol. 35, no. 8, pp. 58-60, 2016.

[16] C. Jin, "On the teaching mode of \"plate concentration \" in basketball teaching in higher vocational colleges\%\"plate concentration $\mid$ " in basketball teaching in higher vocational colleges," Sports Science and Technology, vol. 39, no. 5, p. 143, 2018.

[17] J. Yuguang, "Reflections on the teaching evaluation of public basketball course," Sports Excellence (Academic Edition), vol. 38, no. 2, pp. 22-23, 2019.

[18] S. Lin, "Secondary vocational school basketball teaching present situation and countermeasure analysis," Education Teaching Forum, no. 26, pp. 228-230, 2017.

[19] Y. Yue, H. He, and Y. Hu, "Strategy of the application of flipped classroom in basketball teaching in universities: a case study of Anhui University of Chinese Medicine," Journal of Hefei University of Technology (Social Science Edition), vol. 31, no. 4, pp. 121-124, 2017.

[20] S. Kuo, "Research on new method of basketball teaching and training in higher vocational colleges," Heilongjiang Science, vol. 8, no. 7, pp. 122-123, 2017.

[21] B. Yu, "The application of sports game method in basketball teaching in high school," Heilongjiang Science, vol. 8, no. 13, pp. 58-59, 2017.

[22] B. Xiaojing and H. Yu, "Influential factors and strategies of junior high school basketball teaching," Sports Science and Technology Literature Bulletin, vol. 25, no. 5, p. 68, 2017. 
[23] J. Guangyuan, "Research on basketball teaching reform in higher vocational colleges under the background of sunshine sports," Journal of Liaoning Teachers College (Natural Science Edition), vol. 18, no. 4, pp. 79-80, 2016.

[24] L. Wang, "Analysis of the common basketball teaching mode of training and improvement strategy," Hubei Sports Science and Technology, no. 2, pp. 128-130, 2016.

[25] Z. Xie, "Design of basketball teaching in higher vocational colleges under the guidance of cooperative learning theory," Journal of Jiamusi Education College, no. 12, pp. 284-285, 2016. 